\title{
Allergy related to dental implant and its clinical significance
}

This article was published in the following Dove Press journal:

Clinical, Cosmetic and Investigational Dentistry

19 August 2013

Number of times this article has been viewed

\section{TP Chaturvedi}

Faculty of Dental Sciences, Institute of Medical Sciences, Banaras Hindu University, Varanasi, India
Correspondence: TP Chaturvedi Faculty of Dental Science, Institute of Medical Sciences, Banaras Hindu University, Varanasi, India 221005

Tel +9l 5422309296

Tel +9l 5422368547

Email deanheaddentistry@gmail.com
Abstract: The oral cavity provides an ideal and unique environment for study of biological processes involving metallic dental aids. Dental materials within the mouth interact continually with physiological fluids. Oral tissues are exposed to a veritable bombardment of both chemical and physical stimuli as well as the metabolism of many species of bacteria; yet, for the most part, oral tissues remain healthy. The $\mathrm{pH}$ of saliva varies from 5.2 to 7.8. Teeth, restorations, or any prosthesis including dental implants in the oral cavity have to function in one of the most inhospitable environments in the human body. They are subject to larger temperature and $\mathrm{pH}$ variations than most other parts of the body. Corrosion, the graded degradation of materials by electrochemical attack, is of concern particularly when dental implants are placed in the hostile electrolytic environment provided by the human mouth. Allergic reactions may occur from the presence of ions produced from the corrosion of implants. The present article describes various manifestations of allergic reactions due to implant material in the oral cavity.

Keywords: dental implant, allergy, titanium, corrosion

\section{Introduction}

Artificial and natural teeth, metallic dental implants, as well as restorative materials within the mouth interact continually with physiological fluids. They function in one of the most inhospitable environments in the human body. During 24 hours, restorations and teeth are exposed to a variety of eatables, from tea or coffee causing higher temperatures to ice or cold drinks causing lower temperatures, from fruit juices causing a reduction of $\mathrm{pH}$, to milk or other products causing an increase in $\mathrm{pH}$ in the oral cavity. ${ }^{1}$ Thus, dental materials need to be selected very carefully. Before selecting a material for dental applications, it is necessary to remember that the choice of the material depends on a number of factors such as

1. corrosion behavior,

2. mechanical properties,

3. cost,

4. availability,

5. biocompatibility, and

6. aesthetic appearance.

Thus, for the application of existing and new dental materials it is essential to have a comprehensive knowledge of these attributes.

An allergy may be defined as acute immunological responses that occur when coming into contact with a known antigen. Allergy can either be an immediate humoral response (as a result of antibody/antigen complexes of type I, II, and III reactions) 
or delayed (type IV) cell-mediated response. Type IV delayed-type hypersensitivity is typically associated with implant-related allergic reaction. ${ }^{1,2}$

The materials that have been designed to be implanted inside a live structure with the aims to substitute or regenerate tissue and tissue functions are known as biomaterials. Williams defines biomaterials as those materials that are used in devices for biomedical use designed to interact with biological systems. ${ }^{2}$ Biomaterials are divided into four types: polymers, metals, ceramics, and natural materials.

Although titanium is the preferred choice for dental implants as it is an inert material, if used in oral implants, it may encourage toxic or allergic type I or IV reactions. Allergy due to titanium might be accountable for the failure of implants in some cases (known as "cluster patients"). ${ }^{3}$ It has been documented that the risk of titanium allergy is more prevalent in patients having sensitivity to other metals. In such types of cases, an allergy assessment is suggested to exclude problems related with titanium implants.

Titanium and zirconium are highly reactive metals, and when exposed to fluid media or air they quickly develop a layer of titanium dioxide $\left(\mathrm{TiO}_{2}\right)$ or zirconium dioxide $\left(\mathrm{ZrO}_{2}\right)$. This layer of metal dioxide forms a boundary at the interface between the biological medium and the metal structure and prevents further deterioration of materials. It produces passivation of the metal, determining the degree of biocompatibility and the biological response to the implant. ${ }^{3-5}$ Any rupture of the oxide layer may produce corrosion of these metals and affect biocompatibility. ${ }^{1}$

Furthermore, the insertion of titanium implants and their presence in the human body may also cause internal exposure which ultimately leads to titanium ions to concentrate in tissues, regional lymph nodes, and pulmonary tissue. Concentrations of between 100 and 300 ppm have been discovered in peri-implant tissues, often accompanied by discoloration, which can be well tolerated, ${ }^{6-10}$ or by type IV hypersensitivity reactions, with titanium particles inside the macrophage lysosomes. ${ }^{1-15}$ In an implant failure study, two implants came out without any infection, and in that particular patient, the presence of titanium in the lungs was observed to be 2.2-3.8 times higher than normal, and 7.0-9.4 times higher in the enlarged lymph nodes. ${ }^{15}$

Allergic reaction to a metal comes from the presence of ions following ingestion, skin or mucosal contact, or from implant corrosion processes. ${ }^{16,17}$ These ions, although not sensitizers, form complexes with native proteins and act as allergens causing hypersensitivity reactions. Titanium allergies have presented with signs of urticaria, eczema, edema, redness, and pruritus of the skin or mucosa, either localized, at distant sites, or generalized. ${ }^{18-20}$ In some special cases, allergic reactions have been associated with more serious problems such as atopic dermatitis, impaired healing of fractures, pain, necrosis, and weakening of orthopedic implants and tolerance phenomena. ${ }^{20}$ In the field of implants dentistry, the appearance of facial erythema and non-keratinized, edematous, proliferative hyperplastic tissue have also been described..$^{21}$,

\section{Allergy to implant materials}

The orofacial regions have been associated with types I, III, and IV allergies. One of the most common types of allergy found in the oral cavity is type IV, in which the appearance of characteristic features related to the allergy can start from a few days to several years from contact with allergens. ${ }^{22-26}$

\section{Clinical manifestations of an allergy in the orofacial region}

Patients with an oral allergy demonstrate various clinical features such as burning or tingling sensations, generally associated with swelling, oral dryness, or loss of taste, ${ }^{27}$ or occasionally more common signs and symptoms (eg, headache, dyspepsia, asthenia, arthralgia, myalgia, etc). ${ }^{23,27}$ Allergy in the oral cavity manifests as erythema of the oral mucosa, labial edema, or purpuric patches on the palate, mouth ulcers, hyperplastic gingivitis, depapillation on the tongue, angular cheilitis, perioral eczematous eruption, or lichenoid reactions. ${ }^{23}$ Type I allergy may appear clinically in the orofacial region, in the acute form as swelling, may involve the upper respiratory tract, and be dangerous for the patient. In serious conditions, it may convert to urticarial reactions with or without tingling sensations confined to a small area in the oral or pharyngeal cavity. ${ }^{22}$

\section{Diagnostic tests for allergy}

1. Epicutaneous tests (patch tests): After applying different allergens on the back of the patient, the consequences of the allergens are evaluated, preferably after 48 and 72 hours for the majority of allergens (gold can react late so it can be tested after 10 days). In the positive test for an allergen, the area of skin related to the tested allergen will showed erythematous reactions, vesicles, and etching. Patch tests are limited in use due to their poor sensitivity, which has been demonstrated for approximately $75 \%$ of type IV metal allergies. ${ }^{28}$ Lack of standardization for certain metals like titanium may limit the use of a patch test. ${ }^{29}$ 
2. Type I allergy can be diagnosed by a skin test (prick test) which involves intradermal inoculation of the allergen. It is analyzed within 15 to 30 minutes. ${ }^{30}$ Red, papular, and/or vesicular reactions of the skin may appear in positive test conditions. Prick tests are not recommended for testing of allergy related to a dental material in the oral cavity. Frequently, type IV allergy is associated with dental materials in the oral cavity.

3. The lymphocyte transformation test (LTT) is applied by an in vitro method in mucosal sensitizing allergens. The optimized version of LTT is known as Memory Lymphocyte Immuno Stimulation Assay (MELISA). Local and systemic effects of hypersensitivity resulting from allergies can be analyzed by this method. ${ }^{31,32}$

An allergy evaluation for titanium is suggested in those titanium implant indicated patients who have a history of allergy to other metals. Under hostile circumstances, lower $\mathrm{pH}$ phenomenon in a peri-implantitis region to implant facing extreme mechanical forces, or in the proximity of implant with other metals such as amalgam, gold alloy, or chromiumcobalt alloys, corrosion of titanium may occur. Titanium ions or microparticles of titanium released in the area of periodontal tissue adjacent to the implant can cause inflammatory reactions in the surrounding tissues. ${ }^{33}$ Macrophages, activated by titanium, secrete cytokines which are responsible for the initiation of different diseases. Titanium ions (haptens) released by surface degradation may combine with endogenous proteins to form antigenic molecules due to their high affinity with protein. These antigenic molecules (the allergen) are captured by langerhans cells, related to T-lymphocytes. It produces Type IV allergy, known as delayed-type hypersensitivity reaction to the patient after repeated contact of an allergen with skin or mucosa.

\section{Corrosion and dental implants}

Corrosion is the deterioration of a metal due to interaction (electrochemical attack) with its environment, which results in the release of ions into the surrounding microenvironment. ${ }^{34,35}$ Passivating metals like titanium, vanadium, zirconium, niobium, and tantalum, resist corrosion due to the formation of a surface oxide layer. A recent review of the literature demonstrated that corrosion may become one of the factors for dental implant failure. ${ }^{1,35}$

All of the metallic materials used in implants in tissues are accountable, to a certain degree, to corrosion due to variations in the internal electrolyte environment. When metal particles/ ions are released from the implant surface, they can migrate systemically, remain in the intercellular spaces near the site where they were released, or be taken up by macrophages. ${ }^{36,37}$ The presence of metallic particles in peri-implant tissues may not only be due to a process of electrochemical corrosion, but also to frictional wear, or a synergistic combination of the two. Moreover, mechanical disruption during insertion, abutment connection, or removal of failing implants have been suggested as possible causes of the release of particles from metal structures. $^{34,38}$ The release of particles/ions from the implant into the surrounding biological compartment, their biodistribution in the body, and their final destination are issues that lie at the center of studies on biocompatibility and biokinetics. The potential toxicity and biological risks associated with ions and/ or particles released due to corrosion of metallic implants is a health concern for patients with prostheses (orthopedic and/or dental) due to the long duration that these implants stay inside the body. The corrosion products formed as a result of metalenvironment interactions have an effect on the biocompatibility and long term stability of the prostheses/implants. ${ }^{1}$

Any prior history of allergies of the patient should be evaluated. Metal allergy assessment and allergy testing is recommended in patients prior to the placement of dental implants, to get a successful outcome of implant function. An allergic reaction can be rationally guessed subsequent to metallic implant placement, based on clinical features linked with allergy, such as rash, urticaria, pruritus, oral erythema, swelling in the region, eczematous lesions, or hyperplastic lesions of periodontal tissue (the peri-implant mucosa). In such cases, allergy testing must be carried out.

\section{Discussion}

Since the 1960s, titanium has developed into a well-accepted metallic biomaterial due to its unique properties, with many biomechanical applications including arthroplasty, osteosynthesis, pacemaker cases, oral reconstructive procedures, anchorage of bone conductive hearing aids and epistheses, as well as jewelry for body piercing. It should be noted, however, that no material, including implants, can be considered universally biocompatible. ${ }^{39}$ It is now documented that environmental factors are contributing factors in the increasing occurrence of allergic disorders affecting the world population. ${ }^{40,41}$ It is also known that dental biomaterials discharge substances that alter the oral environment to a varying degree ${ }^{42,43}$ and thus may add to local allergic reactions within the oral tissues. In the oral cavity, an elevated concentration of metal ions may be noxious and act as a local immunosuppressant. In previous studies, it has been recommended that a hypersensitivity reaction due to a titanium implant is of concern for implant longevity. ${ }^{44,45}$ 
Whether titanium dental implants along with allergic reactions like skin rash, flush, and eczema are entirely related to titanium hypersensitivity or not, is a contentious issue. Titanium alloys (mainly titanium, aluminum, and vanadium alloys) are the preferred choice for dental implants as compared to pure titanium, due to their higher strength. However small amounts of other elements associated with titanium alloys can act as "impurities." These element impurities in the titanium implant metals can initiate allergic reactions in patients. Harloff et $\mathrm{al}^{46}$ used spectral analysis to investigate various titanium alloys, such as sponge titanium, $\operatorname{TiAl}_{6} \mathrm{~V}_{4}$, and iodide titanium. The results of their study showed that titanium alloys contained very small amounts of additional elements such as beryllium, cobalt, chromium, copper, iron, nickel, and palladium. Forte et $\mathrm{al}^{29}$ showed that these elements may be causative factors for different allergic reactions in patients with dental implants. In a similar report, Schuh et $\mathrm{al}^{47}$ showed that even a small amount of nickel in titanium alloys may provoke or intensify allergic reactions. In similar ways, aluminum may be linked with persistent granulomas and recurrent eczema, and beryllium causes allergies in the mucosa of the oral cavity. A study related to alloys like copper-beryllium and aluminum-beryllium alloys on guinea pigs showed delayed skin hypersensitivity reactions. ${ }^{10}$ Comparable consequences of the hypersensitivity of some metal impurities in titanium alloys have also been demonstrated by others in different studies; the metal impurities contributed to triggering allergic reactions in patients with dental implants. ${ }^{47}$ More studies are needed to establish the role of pure titanium dental implants in the development of hypersensitivity reactions. In addition, the impact of impurities in titanium alloys, the metals used in prosthetic bridgeworks, may also be a cause for allergic reactions. Nickel and cobalt-based alloys are widely used in prosthetic dentistry for crown and bridge applications; nevertheless, there seems to be no agreement regarding the safety of these alloys. Garhammer et $\mathrm{al}^{24}$ investigated dental cast alloys and reported a great variety of subjective complaints including gingivitis, palatal inflammation, lingua plicata, lingua geographica, and lichenoid reactions of the oral mucosa of the patients. On the other hand, Kulak and Arikan ${ }^{48}$ reported no evidence that dental base metal alloys caused an increase in sensitization.

\section{Conclusion}

No metal or alloy is completely inert in vivo. All metals will undergo a slow removal of ions from the surface, largely because of local and temporal variations in microstructure and environment. The current massive use of these metal biomaterials in the biomedical field renders it necessary to have detailed knowledge not only of their early effects (short term failure), but also of their long term effects, with consideration that these materials remain inside the patients over long periods of time, sometimes throughout their entire life. The potential risk of corrosion and the possible detrimental consequences of its byproducts are significant issues of clinical importance. The biologic effect of the corrosion of dental implants is an important health issues associated with any metal prosthesis in the body. The presence of ions/particles and their potential local biological effects around metallic devices might affect implant outcome. A sensitive and precise test which will help to determine titanium hypersensitivity should be developed.

\section{Disclosure}

The author reports no conflicts of interest in this work.

\section{References}

1. Chaturvedi TP. An overview of the corrosion aspect of dental implants (titanium and its alloys). Indian J Dent Res. 2009;20(1):91-98.

2. Williams DF. European Society for Biomaterials. Definitions in Biomaterials, Proceedings of a Consensus Conference of the European Society for Biomaterials, Chester, England, March 3-5,1986. Amsterdamn: Elsevier; 1987.

3. Chuang S, Cai T, Douglass C, Wei L, Dodson T. Frailty approach for the analysis of clustered failure time observation in dental research. J. Dent Res., 2005;84:54-58.

4. Kasemo B, Lausmaa J. Biomaterial and implant surfaces: a surface science approach. Int J Oral Maxillofac Implants. 1988;3(4):247-259.

5. Long M, Rack HJ. Titanium alloys in total joint replacement - a materials science perspective. Biomaterials. 1998;19(18):1621-1639.

6. Parr GR, Gardner LK, Toth RW. Titanium: the mystery metal of implant dentistry. Dental materials aspects. J Prosthet Dent. 1985;54(3): 410-414.

7. Abdallah HI, Balsara RK, O'Riordan AC. Pacemaker contact sensitivity: clinical recognition and management. Ann Thorac Surg. 1994;57(4): 1017-1018.

8. Torgersen S, Gjerdet NR, Erichsen ES, Bang G. Metal particles and tissue changes adjacent to miniplates. A retrieval study. Acta Odontol Scand. 1995;53(2):65-71.

9. Haug RH. Retention of asymptomatic bone plates used for orthognathic surgery and facial fractures. J Oral Maxillofac Surg. 1996;54(5): 611-617.

10. Matthew IR, Frame JW. Ultrastructural analysis of metal particles released from stainless steel and titanium miniplate components in an animal model. J Oral Maxillofac Surg. 1998;56(1):45-50.

11. Mitchell DL, Synnott SA, VanDercreek JA. Tissue reaction involving an intraoral skin graft and CP titanium abutments: a clinical report. Int J Oral Maxillofac Implants. 1990;5(1):79-84.

12. Lalor PA, Revell PA, Gray AB, Wright S, Railton GT, Freeman MA. Sensitivity to titanium. A cause of implant failure? J Bone Joint Surg Br. 1991;73(1):25-28.

13. Revell PA, Lalor PA. Massive exposition to titanium, but without sensitization. Acta Orthop Scand. 1995;66(5):484.

14. Katou F, Andoh N, Motegi K, Nagura H. Immuno-inflammatory responses in the tissue adjacent to titanium miniplates used in the treatment of mandibular fractures. J Craniomaxillofac Surg. 1996;24(3): $155-162$. 
15. Frisken KW, Dandie GW, Lugowski S, Jordan G. A study of titanium release into body organs following the insertion of single threaded screw implants into the mandibles of sheep. Aust Dent J. 2002;47(3): 214-217.

16. Ahnlide I, Björkner B, Bruze M, Möller H. Exposure to metallic gold in patients with contact allergy to gold sodium thiosulfate. Contact Dermatitis. 2000;43(6):344-350.

17. Hallab N, Merritt K, Jacobs JJ. Metal sensitivity in patients with orthopaedic implants. Journal of Bone and Joint Surgery - American. 2001;83(A):428-436.

18. Hensten-Pettersen A. Casting alloys: side-effects. Adv Dent Res. 1992;6: 38-43.

19. Lhotka CG, Szekeres T, Fritzer-Szekeres M, et al. Are allergic reactions to skin clips associated with delayed wound healing? Am J Surg. 1998;176(4):320-323.

20. Thomas P. Allergological aspects of implant biocompatibility. In: Willmann G, editor. Bioceramics in Hip Joint Replacement: Proceedings 5th International CeramTec Symposium, Febr. 18/19, 2000; 25 Tables, 117-121. New York: George Thieme Verlag; 2000.

21. Matthew I, Frame JW. Allergic responses to titanium. J Oral Maxillofac Surg. 1998;56(12):1466-1467.

22. Gawkrodger DJ. Investigation of reactions to dental materials. $\mathrm{Br} J$ Dermatol. 2005;153(3):479-485.

23. Vamnes JS, Lygre GB, Grönningsaeter AG, Gjerdet NR. Four years of clinical experience with an adverse reaction unit for dental biomaterials. Community Dent Oral Epidemiol. 2004;32(2):150-157.

24. Garhammer P, Schmalz G, Hiller KA, Reitinger T, Stolz W. Patients with local adverse effects from dental alloys: frequency, complaints, symptoms, allergy. Clin Oral Investig. 2001;5(4):240-249.

25. LeSueur BW, Yiannias JA. Contact stomatitis. Dermatol Clin 2003;21(1):105-114, vii.

26. Evrard L, Parent D. Oral allergies to dental materials. Review of the literature and report of three cases. Bull Group Int Rech Stomatol. Odontol., 2010; 49: 14-19.

27. Lygre GB, Gjerdet NR, Grønningsaeter AG, Björkman L. Reporting on adverse reactions to dental materials: intraoral observations at a clinical follow-up. Community Dent Oral Epidemiol. 2003;31(3):200-206.

28. Okamura T, Morimoto M, Fukushima D, Yamane G. J Dent Res. 1999;78:1135.

29. Forte G, Petrucci F, Bocca B. Metal allergens of growing significance: epidemiology, immunotoxicology, strategies for testing and prevention. Inflamm Allergy Drug Targets. 2008;7(3):145-162.

30. Yamauchi R, Morita A, Tsuji T. Pacemaker dermatitis from titanium. Contact Dermatitis. 2000;42(1):52-53.

31. Stejskal VD, Cederbrant K, Lindvall A, Forsbeck M. MELISA-an in vitro tool for the study of metal allergy. Toxicol In Vitro. 1994;8(5): 991-1000.
32. Müller K, Valentine-Thon E. Hypersensitivity to titanium: clinical and laboratory evidence. Neuro Endocrinol Lett. 2006;27 Suppl 1:31-35.

33. Messer, Wahata. Dental materials: biocompatibility. In: Buschow KHJ, editor. Encyclopedia of Materials: Science and Technology. Amsterdamn: Elsevier; 2002:1-10.

34. Jacobs J, Gilbert J, Urban R. Current Concepts Review - Corrosion of Metal Orthopaedic Implants. J Bone Joint Surg Am. 1998;80(2): 268-282.

35. Chaturvedi TP, Upadhayay SN. An overview of orthodontic material degradation in oral cavity. Indian J Dent Res. 2010;21(2):275-284.

36. Olmedo D, Fernández MM, Guglielmotti MB, Cabrini RL. Macrophages related to dental implant failure. Implant Dent. 2003;12(1):75-80.

37. Olmedo DG, Tasat D, Guglielmotti MB, Cabrini RL. Titanium transport through the blood stream. An experimental study on rats. J Mater Sci Mater Med. 2003;14(12):1099-1103.

38. Flatebø RS, Johannessen AC, Grønningsaeter AG, et al. Host response to titanium dental implant placement evaluated in a human oral model. J Periodontol. 2006;77(7):1201-1210.

39. Williams DF. Titanium: epitome of biocompatibility or cause for concern. J Bone Joint Surg Br. 1994;76(3):348-349.

40. National Research Council. Biologic Markers in Immunotoxicology. Washington, DC: National Academy Press; 1992.

41. Mösges R. The increasing prevalence of allergy: a challenge for the physician. Clin Exp Allergy. 2002;2(1):13-17.

42. Schmalz G, Garhammer P. Biological interactions of dental cast alloys with oral tissues. Dent Mater. 2002;18(5):396-406.

43. Schedle A, Ortengren U, Eidler N, Gabauer M, Hensten A. Do adverse effects of dental materials exist? What are the consequences, and how can they be diagnosed and treated? Clin Oral Implants Res. 2007; 18 Suppl 3:232-256.

44. Okamura T, Morimoto M, Fukushima D, Yamane G. A skin patch test for the diagnosis of titanium allergy. Journal of Dental Research. 1999;78:1135.

45. Olmedo DG, Paparella ML, Brandizzi D, Cabrini RL. Reactive lesions of peri-implant mucosa associated with titanium dental implants: a report of 2 cases. Int J Oral Maxillofac Surg. 2010;39(5): 503-507.

46. Harloff T, Hönle W, Holzwarth U, Bader R, Yhomas P, Schuh A Titanium allergy or not? "Impurity" of titanium implant materials. Health. 2010;2(4):306-310.

47. Schuh A, Thomas P, Kachler W, et al. Allergic potential of titanium implants. Orthopade. 2005;34(4):327-328, 330-333. German.

48. Kulak Y, Arikan A. Effect of dental base metal alloys on IgE levels and some blood parameters. J Oral Rehabil. 1997;24(10):749-754.

Clinical, Cosmetic and Investigational Dentistry

\section{Publish your work in this journal}

Clinical, Cosmetic and Investigational Dentistry is an international, peer-reviewed, open access, online journal focusing on the latest clinical and experimental research in dentistry with specific emphasis on cosmetic interventions. Innovative developments in dental materials, techniques and devices that improve outcomes and patient satisfaction

and preference will be highlighted. The manuscript management system is completely online and includes a very quick and fair peerreview system, which is all easy to use. Visit http://www.dovepress. com/testimonials.php to read real quotes from published authors. 